\title{
Costs of implementing and sustaining enhanced collaborative care programs involving community partners
}

\author{
Theresa J. Hoeft ${ }^{{ }^{*}}$ (D), Heather Wilcox ${ }^{1}$, Ladson Hinton ${ }^{2}$ and Jürgen Unützer ${ }^{1}$
}

\begin{abstract}
Background: Collaborative care is an evidence-based program for treating depression in primary care. We sought to expand this model by recruiting clinics interested in incorporating community partners (i.e., community-based organizations (CBO) and/or family members) in the care team. Seven sites implemented evidence-based collaborative care programs with community partners while collecting information on costs of implementing and sustaining programs.

Methods: Sites retrospectively collected data on planning and implementation costs with technical assistance from study researchers. Sites also prospectively collected cost of care activities over a 1-month period once the program was implemented to determine resources needed to sustain programs. Personnel salary costs were adjusted, adding 30\% for benefits and 30\% for administrative overhead.

Results: The programs implemented varied considerably in staffing, involvement of care partners, and allocation of costs. Total planning and implementation costs varied from $\$ 39,280$ to $\$ 60,575$. The largest implementation cost category involved workflow development and ranged from $\$ 16,325$ to $\$ 31,375$ with the highest costs in this category attributed to the most successful implementation among clinic-CBO programs. Following implementation, cost per patient over the 1month period ranged from \$154 to \$544. Ongoing strategic decision-making and administrative costs, which were included in cost of care, ranged from $\$ 284$ to $\$ 2328$ for the month.

Conclusions: Sites implemented collaborative care through differing partnerships, staffing, and related costs. Costs to implement and sustain programs developed in partnership are often not collected but are crucial to understanding financial aspects of developing sustainable partnerships. Assessing such costs is feasible and can inform future partnership efforts.
\end{abstract}

Keywords: Collaborative care implementation, Adaptation, Community partners, Family, Depression, Older adults

\section{Background}

Depression is common in older adults and comes at a high cost to patients and their families. Major depression affects $2-5 \%$ of community-dwelling older adults and 5$10 \%$ of older adults in primary care settings [1-4]. Late-life depression impairs quality of life [5] and ability to function and enjoy old age [6]. It is associated with increased healthcare costs $[7,8]$, family stress, and

\footnotetext{
* Correspondence: thoeft@uw.edu

${ }^{1}$ Department of Psychiatry and Behavioral Sciences, University of Washington

School of Medicine, Box 356560, Seattle, WA 98195-6560, USA
}

Full list of author information is available at the end of the article increased risk of suicide. Depression is the most important-and most treatable-risk factor for suicide [9].

Over the past two decades, significant progress has been made in our ability to diagnose and treat depression in older adults. Research has demonstrated that collaborative care programs in which primary care providers (PCPs) are supported by mental health professionals to treat depression in older adults can dramatically improve the effectiveness and cost-effectiveness of depression treatment [10-13]. Collaborative care involves a primary care-based team, including a care manager who tracks depression symptoms and offers brief psychotherapy and/or medication management, a psychiatric consultant who consults

(c) The Author(s). 2019 Open Access This article is distributed under the terms of the Creative Commons Attribution 4.0 International License (http://creativecommons.org/licenses/by/4.0/), which permits unrestricted use, distribution, and reproduction in any medium, provided you give appropriate credit to the original author(s) and the source, provide a link to the Creative Commons license, and indicate if changes were made. The Creative Commons Public Domain Dedication waiver (http://creativecommons.org/publicdomain/zero/1.0/) applies to the data made available in this article, unless otherwise stated. 
with the care manager on a weekly basis about a caseload of patients tracked in a registry, and the patient's PCP.

Despite these advances, many depressed older adults either do not access treatment or fail to engage sufficiently in treatment to benefit. Vulnerable groups at particularly high risk for ineffective depression care include minorities, older men, and older adults with multiple medical problems, less formal education, or lower socioeconomic status [14-16]. Closing gaps in care to improve access to effective depression treatment is important and timely.

One of the most promising approaches to improving the reach and effectiveness of late-life depression care builds on task shifting, or task sharing, in mental health care delivery [17] which involves sharing care delivery tasks with typically less highly skilled clinicians and staff to allow each to work to the top of their license [18-20]. Task sharing can enhance care by broadening the scope of care delivery tasks. Collaborative care, for example, includes repeated depression symptom monitoring and tracking patients in a registry which were previously not standard elements of depression care. A review of the literature on future directions for late-life depression care identified the promise of task sharing to involve family members and community-based organizations $(\mathrm{CBO})$ in depression care [16]. Often, these community partners have eyes and ears in the community and thus can enhance depression care through improving access to care, engagement in treatment both initially and during depression relapse, and the patient care experience for depressed older adults.

As part of a late-life depression initiative in California, seven sites were awarded funding for a period of 2 years to implement an enhanced collaborative care model that incorporated a $\mathrm{CBO}$ and/or family member(s) of the older adult in the collaborative care team. Core principles of collaborative care were maintained in the implementation, so modifications only involved expanding the care team and offering care in settings outside primary care (e.g., CBOs and home visits). A task matrix of all collaborative care tasks ensured programs included all aspects of collaborative care.

Costs associated with program implementation and operation are infrequently collected but critical to program success and sustainability. As sites implemented their partnered models of care in 2015, a program evaluation included assessment of (1) planning and implementation costs and (2) costs to operate and sustain the model of care following the implementation period. Costs were assessed based on detailed spreadsheets of tasks completed and associated hours, salaries, and non-personnel costs. This information enabled us to study ways in which tasks are shared across organizations; the overall costs associated with planning, implementation, and cost of care delivery; and additional costs that may be attributed to working in partnership.

As evidenced within recent developments in the USA of Accountable Care Organizations and Accountable Health Communities, value-driven health care is increasingly looking to community partnerships to improve care for complex patients [21,22]. Costs associated with working in partnership are not typically studied but are crucial to understanding resources necessary to carry out this important work. This study outlines costs associated with partnered implementation of collaborative care, a process however that could be applied to any implementation of an evidence-based practice.

\section{Methods}

\section{Data collection}

Two pilot sites gave feedback on the data collection plan, guidance documents, and preferences for reporting results back to the sites. One person at each organization who was most familiar with project activities utilized Excel ${ }^{\circ}$ spreadsheets to collect project-specific activities (i.e., activity description, time spent, salaries, non-personnel costs) for both the planning + implementation periods and the 1-month care delivery period which fell within the sustainment period. Spreadsheet items are further described in Additional file 1. Planning and implementation periods were delineated by the notice of grant award, enrollment of the first patient, and date when the site's major workflow changes came to an end. The decision to end the implementation period when workflow changes declined was based on feedback from the pilot sites that a standard 3or 6-month period for the implementation timeframe would not fit each site's implementation. The resulting implementation periods ranged from 1.5 months (through January 2016) to almost 9 months (through August 2016). The sustainment period, when cost of care data was collected, followed the implementation period. Most sites completed the cost of care spreadsheet in October 2019 which fell between 2 and 9 months after their implementation period ended and sustainment period began.

Study researchers supported data collection at each site through a minimum of two telephone calls, reviewing drafts of spreadsheets to anticipate issues and questions, and responding to additional questions by email and telephone. Since the cost evaluation study began 6 months after the sites' grants were awarded, sites retrospectively collected costs associated with planning + implementation activities. Once the model was implemented, sites prospectively recorded 1-month cost of care activities. Midway through the cost of care data collection, sites were asked to submit a draft spreadsheet to address questions and anticipate potential missing data early on.

Data collection spreadsheets separated costs into pre-specified categories of interest based largely on a 
previous study of collaborative care in the COMPASS implementation [23, 24]. Planning + implementation costs were collected within the categories of developing and training new roles, developing workflows and preparing existing staff, project oversight and strategic decision-making, registry/IT expenses, and other costs. Each organization then additionally separated activities on the spreadsheets by whether they occurred in the planning period or implementation period. Costs of care activities were collected under major categories associated with collaborative care including care manager time, psychiatric consultant + PCP champion time, strategic decision-making, care manager supervision + administrative management, registry/IT and quality improvement (QI), and other costs.

\section{Analysis}

While the pre-specified cost categories in the spreadsheets informed the cost summaries, review of the spreadsheets suggested additional categories. The majority of activities reported in this partnered implementation involved workflow development and other planning costs specifically done either in partnership or individually within each organization. Details of care managers' time revealed additional richness of the data. We thus used the original categories as a guide, but allowed for new areas of synthesis to be revealed in the data-an approach similar to deductive and inductive qualitative research. Each activity had an associated number of hours rounded to the quarter hour and associated salary for all staff members in the activity. Sites were given an option to provide actual salaries or average salaries for the position. For one site without salary information, we used the Bureau of Labor Statistics salary information for that region in California. Costs were summarized by a priori categories of interest and categories later identified upon review of the cost data. Personnel salary costs were adjusted by adding 30\% for benefits and an additional 30\% for administrative overhead. Patient demographic differences across sites in Table 1 were assessed using Pearson's chi-square test.

\section{Results}

Sites overview

Sites selected to join the initiative all tended to work with low-income, diverse populations as is described through program participants in Table 1 . By design, all patients were $65+$ years old. Two sites saw a substantial number of patients across all age groups while four sites recruited primarily older adults who were 65-69 years of age. One site working with primarily older home-bound individuals enrolled a majority of their patients in the $80+$ age group

Table 1 Patient participant demographics by site

\begin{tabular}{|c|c|c|c|c|c|c|c|c|c|}
\hline & $\begin{array}{l}\text { Site } 1 \\
(n=51)\end{array}$ & $\begin{array}{l}\text { Site } 2 \\
(n=11)\end{array}$ & $\begin{array}{l}\text { Site } 3 \\
(n=24)\end{array}$ & $\begin{array}{l}\text { Site } 4 \\
(n=47)\end{array}$ & $\begin{array}{l}\text { Site } 5 \\
(n=75)\end{array}$ & $\begin{array}{l}\text { Site } 6 \\
(n=37)\end{array}$ & $\begin{array}{l}\text { Site } 7 \\
(n=29)\end{array}$ & $\begin{array}{l}\text { Total } \\
(n=274)\end{array}$ & $p$ value \\
\hline \multicolumn{10}{|l|}{ Age, $n(\%)$} \\
\hline $65-69$ & $28(54.9)$ & $5(45.5)$ & $13(54.2)$ & $3(6.4)$ & $29(38.7)$ & $21(56.8)$ & $7(24.1)$ & $106(38.7)$ & \\
\hline $70-74$ & $12(23.5)$ & $2(18.2)$ & $7(29.2)$ & $8(17.0)$ & $17(22.7)$ & $8(21.6)$ & $10(34.5)$ & $64(23.4)$ & \\
\hline $75-79$ & $5(9.8)$ & $2(18.2)$ & $2(8.3)$ & $9(19.1)$ & $13(17.3)$ & $5(13.5)$ & $6(20.7)$ & $42(15.3)$ & \\
\hline $80+$ & $6(11.8)$ & $2(18.2)$ & $2(8.3)$ & $27(57.4)$ & $16(21.3)$ & $3(8.1)$ & $6(20.7)$ & $62(22.6)$ & $<0.001$ \\
\hline \multicolumn{10}{|l|}{ Gender, n (\%) } \\
\hline Male & $20(39.2)$ & $0(0.0)$ & $14(58.3)$ & $16(34)$ & $14(18.7)$ & $11(29.7)$ & 28 (96.6) & $103(37.6)$ & \\
\hline Female & $31(60.8)$ & $11(100)$ & $10(41.7)$ & $31(66)$ & $61(81.3)$ & $26(70.3)$ & $1(3.4)$ & $171(62.4)$ & $<0.001$ \\
\hline \multicolumn{10}{|l|}{ Race/ethnicity, n (\%) } \\
\hline Hispanic & $20(39.2)$ & $7(63.6)$ & $1(4.2)$ & $6(12.8)$ & $26(34.7)$ & $37(100)$ & $5(17.2)$ & $102(37.2)$ & \\
\hline Black & $9(17.6)$ & $1(9.1)$ & $10(41.7)$ & $3(6.4)$ & $0(0.0)$ & $0(0.0)$ & $1(3.4)$ & $24(8.8)$ & \\
\hline Asian & $3(5.9)$ & $0(0.0)$ & $0(0.0)$ & $7(14.9)$ & $2(2.7)$ & $0(0.0)$ & $4(13.8)$ & $16(5.8)$ & \\
\hline Multiple reported & $1(2.0)$ & $0(0.0)$ & $0(0.0)$ & $1(2.1)$ & $2(2.7)$ & $0(0.0)$ & $0(0.0)$ & $4(1.5)$ & \\
\hline White, non-Hispanic & $16(31.4)$ & $2(18.2)$ & $11(45.8)$ & $26(55.3)$ & $44(58.7)$ & $0(0.0)$ & $19(65.5)$ & $118(43.1)$ & \\
\hline Missing & $2(3.9)$ & $1(9.1)$ & $2(8.3)$ & $4(8.5)$ & $1(1.3)$ & $0(0.0)$ & $0(0.0)$ & $10(3.6)$ & $<0.001$ \\
\hline Interpreter needed, $n$ (\%) & $1(2.0)$ & $5(45.5)$ & $0(0.0)$ & $0(0.0)$ & $0(0.0)$ & $1(2.7)$ & $0(0.0)$ & 7 (2.6) & $<0.001$ \\
\hline \multicolumn{10}{|l|}{ Preferred language, $n$ (\%) } \\
\hline English & 35 (68.6) & $4(36.4)$ & $24(100.0)$ & $47(100.0)$ & $54(72.0)$ & $0(0.0)$ & $29(100.0)$ & $193(70.4)$ & \\
\hline Spanish & $14(27.5)$ & $6(54.5)$ & $0(0.0)$ & $0(0.0)$ & $21(28.0)$ & $37(100)$ & $0(0.0)$ & $78(25.8)$ & \\
\hline Other & $2(4.0)$ & $1(9.1)$ & $0(0.0)$ & $0(0.0)$ & $0(0.0)$ & $0(0.0)$ & $0(0.0)$ & $3(1.2)$ & $<0.001$ \\
\hline
\end{tabular}


(site 4). Two sites served predominantly men (96.6\% in a VA clinic (site 7) and $58.3 \%$ in a non-VA clinic (site 3 )), while a site utilizing female community health workers (CHWs) offering home visits served only women (100\% of enrollees) (site 2). Two sites served a predominately Hispanic population (63.6\% and 100\%) (sites 2 and 6), while other sites varied in their level of engagement with diverse groups. Finally, the patients' preferred language was often Spanish, particularly at the two sites that enrolled a higher percentage of Hispanic participants.

Sites differed in types of partnerships they developed alongside primary care and size of their primary care networks. Three sites involved a senior center as the CBO partner (sites 1, 3, and 6). Three other sites offered a majority of care via home visits delivered by CBO staff from a health education outreach organization (site 2), an in-home supportive services organization focusing on in-home psychotherapy (site 4), and a health and human services agency (site 5). Two sites involved family in care (sites 6 and 7), though site 7 did not include a CBO partner. Each site started their program development at one clinic with the exception of site 6 which started in two clinics. Most clinic partners fell within organizations comprised of three or more primary care clinics with the exception of sites 2 and 5 .

Sites also differed considerably in terms of staffing composition (e.g., professional background and licensure of staff), with staffing composition sometimes changing mid-way through the grant period due to either turnover or development of a new clinical workflow. Further details on the original mix of care managers at each site are listed in Fig. 1. Sites 2 and 3 employed CHWs with varying levels of training. Sites 1 and 7 employed PsyDor PhD-trained therapists, though following turnover in this position, site 1 shifted to utilizing licensed clinical social worker (LCSW) staff. Site 6 mixed master's-level therapists with bachelor's-level case managers in the clinic setting to split regular depression symptom monitoring and case management tasks. Site 6 also paired the clinic team with a bachelor's-level social worker from the senior center to enhance family engagement in care and facilitate referrals between the two organizations. Site 4 utilized psychology interns, their supervisor, and a postdoctoral fellow for additional support to offer psychotherapy in the home and monitor symptoms. One site that originally relied on two master's-level case managers at the senior center to help engage patients in care ended their formal partnership with the senior center for this project mid-grant (site 1). The clinic then hired a case manager to join the clinic care team to more proactively reach out to older adults who may need local social services, connect them to these services, and report back to care managers and the psychiatric consultant on the patients' progress in reaching needed services.

Care processes also differed across sites and consequently influenced costs of care. For example, collaborative care typically involves a blend of office-based clinic visits and phone contacts to improve engagement in care and opportunities for the care managers to check in on patients. Home visits were a unique aspect of care across

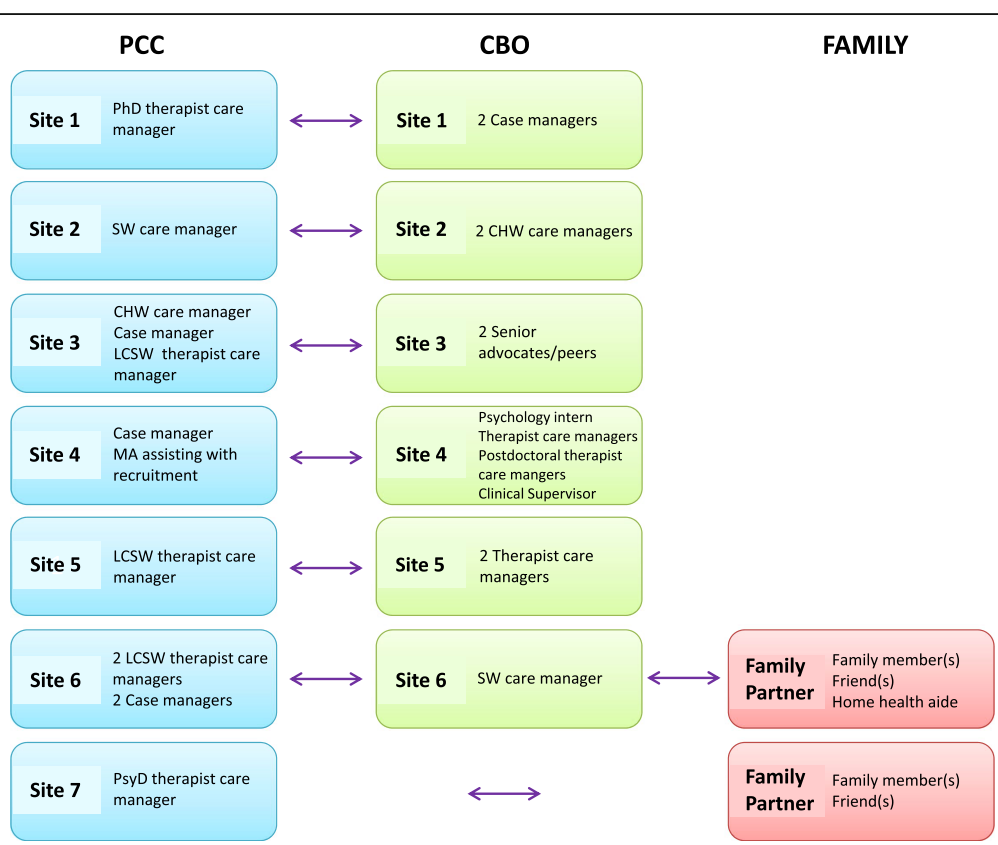

Fig. 1 Care manager team composition variation across sites. PCC, primary care clinic; CBO, community-based organization; SW, social worker; LCSW, licensed clinical social worker; CHW, community health worker 
several sites in this implementation project. In-person visits with a care manager at the clinic ranged from less than one visit $(0.62$ visit) to 18.9 visits on average per person. Clinic visits should have been one or greater per patient to indicate sharing of depression care and clinic involvement (e.g., to help rule out physical causes of depression). Sites on the lower end of this range for clinic-based care tended to be $\mathrm{CBO}$ with weaker connections to primary care (sites 2 and 4), while the site with the most in-person visits employed a large team of care managers at the clinics who reached out on a regular basis. Most sites, however, provided on average 3.0 to 7.8 clinic visits per patient. Two of the three programs that included home visits in care involved fairly minimal care management activities within the clinic system (sites 2 and 4), while the third located the home-visiting care manager in a shared office at the clinic with the LCSW clinic care manager and actively shared care on their caseload of patients (site 5). Phone contact was low across sites with the exception of two sites which provided 5.0 and 8.2 calls per patient on average (sites 5 and 6 respectively). Site 6 thus had the highest number of phone and clinic visits per patient. Three sites offered home visits, and patients received on average 3.3, 8.4, and 9.8 home visits (sites 5, 2, and 4 respectively). Site 4 thus had the lowest number of phone and clinic visits and the highest number of home visits. Care was offered in-person at the $\mathrm{CBO}$, but this was infrequent.

Involvement of the psychiatric consultant in care is another aspect that influenced costs. At six of the sites, the total percent of patients enrolled that were ever discussed at a weekly case review with the psychiatric consultant ranged from 39.2 to $65.3 \%$. The seventh site discussed $100 \%$ of their patients with the psychiatric consultant, though the site enrolled few patients overall perhaps making these cases easier to discuss (site 2).

In terms of depression treatment outcomes, once engaged in the program, all sites were able to improve depression symptoms for patients as measured by the Patient Health Questionnaire-9 (PHQ-9). Of the 274 patients enrolled in care, 247 patients had two or more visits when a PHQ-9 was recorded. For this sample, 62\% of patients showed a $50 \%$ or greater improvement from their initial PHQ-9 score and/or their last PHQ-9 score was less than 10, while $59 \%$ showed improvement of 5 points or more from their initial PHQ-9 score. A total of $32 \%$ achieved a score of less than 5 on their final PHQ-9, which is considered to be remission from depression.

\section{Planning + implementation costs}

Complete planning and implementation cost data were collected on four sites, three involving a $\mathrm{CBO}$ and one including family care partners. Site 6 declined to participate due to high turnover in key leadership and administrative positions and thus lost critical knowledge about planning and implementation activities. Two sites (sites 1 and 2) offered incomplete data due to the ending of their formal partnerships near the due date for data collection, though several of their costs can be compared to other sites (e.g., clinic costs spent on workflow development). The clinic contact at site 2 omitted the clinic implementation costs. The time the clinic spent on joint activities with the $\mathrm{CBO}$, however, were estimated from the CBO's documentation of clinic meeting attendees at joint administrative meetings in the implementation period. The CBO contact at site 1 could not be reached to collect planning and implementation cost data after their formal partnership for the program ended.

Planning and implementation costs by type of expense (e.g., training, workflow development, other planning activities) are presented in Table 2. For sites involving a CBO partner, the majority (52-65\%) of costs were associated with shared workflow development and non-workflow-related planning (Fig. 2). The most successful clinic-CBO implementation (site 5) accrued the highest costs for workflow and non-workflow planning activities, totaling $\$ 31,375$ (Table 2). In contrast, total costs for workflow development and other planning activities at the other clinic-CBO sites with complete data were $\$ 16,325$ and $\$ 19,170$ (Fig. 2). At the family care partner clinic that did not partner with a CBO (site 7), these workflow and non-workflow planning activities totaled $\$ 16,809$.

Training and other expense categories also varied by site. Training costs were higher for three sites (sites 1, 2 and 4). Site 4 is a training program for psychology interns, so many training activities for interns were offered by supervisors at the $\mathrm{CBO}$, though notably, intern costs were documented as in-kind hours. Site 2 faced low patient enrollment and trouble recruiting and thus engaged staff in additional training activities (e.g., re-watching webinars) with available time not spent on patient care in the implementation period. Site 1 experienced turnover of two key leadership positions and their original care manager within the planning and implementation periods. Other costs varied in large part due to larger registry/IT costs at some sites (e.g., for the $\mathrm{CBO}$ to gain $\mathrm{read} / \mathrm{write}$ or read-only access to the clinic's electronic health record) or due to longer implementation periods that then covered the initiative's annual meeting and thus related travel expenses.

Total planning and implementation costs for sites with complete data varied from $\$ 39,280$ to $\$ 60,575$ (Table 3). Three of the sites reported a majority of hours spent in the planning phase, while one site reported comparable hours in planning and implementation phases, in part due to a longer implementation period of 9 months. In clinic-CBO partnerships with complete data, the 
Table 2 Planning and implementation costs across sites by organization and expense category (cost and time spent)

\begin{tabular}{|c|c|c|c|c|c|c|c|c|c|}
\hline Expense category & $\begin{array}{l}\text { Site } 3 \\
\text { clinic }^{a}\end{array}$ & $\begin{array}{l}\mathrm{CBO} \\
\text { partner }\end{array}$ & $\begin{array}{l}\text { Site } 4 \\
\mathrm{CBO}^{\mathrm{a}}\end{array}$ & $\begin{array}{l}\text { Clinic } \\
\text { partner }\end{array}$ & $\begin{array}{l}\text { Site } 5 \\
\mathrm{CBO}^{\mathrm{a}}\end{array}$ & $\begin{array}{l}\text { Clinic } \\
\text { partner }\end{array}$ & $\begin{array}{l}\text { Family site } \\
7 \text { clinic }^{\mathrm{a}}\end{array}$ & $\begin{array}{l}\text { Site } 1 \\
\text { clinic }^{\text {ab }}\end{array}$ & $\begin{array}{l}\text { Site } 2 \\
\mathrm{CBO}^{\mathrm{b}}\end{array}$ \\
\hline \multirow[t]{2}{*}{ Training: new roles ( $\$$, hours) } & $\$ 2958.67$ & $\$ 1030.90$ & $\$ 8327.10$ & $\$ 898.17$ & $\$ 1359.07$ & $\$ 2487.55$ & $\$ 1718.86$ & $\$ 12,015.25$ & $\$ 9822.80$ \\
\hline & 138.5 & 26.5 & 262 & 15 & 27 & 44.5 & 55 & 112.5 & 491 \\
\hline \multirow[t]{2}{*}{ Training: existing staff in existing roles ( $\$$, hours) } & $\$ 327.60$ & $\$ 995.80$ & $\$ 1211.29$ & $\$ 4594.49$ & $\$ 2334.04$ & $\$ 2273.34$ & $\$ 6284.43$ & $\$ 1788.15$ & $\$ 773.50$ \\
\hline & 9 & 26 & 19 & 37 & 38 & 23 & 75.5 & 29.5 & 35 \\
\hline \multirow[t]{2}{*}{ Total for training ( $\$$, hours) } & $\$ 6872.97$ & & $\$ 15,031.0$ & & $\$ 8454.00$ & & $\$ 8003.29$ & $\$ 13,803.40$ & $\$ 10,596.30$ \\
\hline & 200 & & 333 & & 132.5 & & 130.5 & 142 & 526 \\
\hline \multirow[t]{2}{*}{ Workflow development: with partner ( $\$$, hours) } & $\$ 2204.80$ & $\$ 2204.80$ & $\$ 1462.45$ & $\$ 2330.69$ & $\$ 3881.81$ & $\$ 5508.89$ & & $\$ 2850.90$ & $\$ 665.60$ \\
\hline & 58 & 56 & 50 & 33 & 68.5 & 86 & & 45 & 29 \\
\hline \multirow[t]{2}{*}{ Workflow development: solo planning ( $\$$, hours) } & $\$ 1410.50$ & $\$ 325.65$ & $\$ 1241.86$ & $\$ 640.64$ & $\$ 3370.29$ & $\$ 1457.64$ & $\$ 4646.86$ & $\$ 470.60$ & $\$ 6319.30$ \\
\hline & 43.5 & 8.5 & 36.5 & 5 & 57 & 13 & 56 & 8 & 283.5 \\
\hline \multirow[t]{2}{*}{ Total for workflow development ( $\$$, hours) } & $\$ 6145.75$ & & $\$ 5675.64$ & & $\$ 14,218.63$ & & $\$ 4646.86$ & $\$ 3321.50$ & $\$ 6984.90$ \\
\hline & 166 & & 124.5 & & 224.5 & & 56 & 53 & 312.5 \\
\hline \multirow[t]{2}{*}{ Other planning activities: with partner ( $\$$, hours) } & $\$ 6205.94$ & $\$ 1778.40$ & $\$ 845.54$ & $\$ 3831.67$ & $\$ 4490.45$ & $\$ 3168.58$ & & $\$ 2077.40$ & $\$ 2611.70$ \\
\hline & 135 & 45 & 44 & 36.5 & 73 & 51 & & 30 & 112 \\
\hline \multirow[t]{2}{*}{ Other planning activities: solo planning ( $\$$, hours) } & $\$ 3976.70$ & $\$ 1063.40$ & $\$ 4178.17$ & $\$ 1793.79$ & $\$ 7552.21$ & $\$ 1945.06$ & $\$ 12,162.25$ & $\$ 1673.10$ & $\$ 4882.80$ \\
\hline & 104.5 & 21 & 93.5 & 14 & 117 & 29.5 & 125 & 28 & 197 \\
\hline \multirow[t]{2}{*}{ Total for other planning activities ( $\$$, hours) } & \multicolumn{2}{|l|}{$\$ 13,024.44$} & \multicolumn{2}{|c|}{$\$ 10,649.18$} & \multicolumn{2}{|l|}{$\$ 17,156.30$} & $\$ 12,162.25$ & $\$ 3750.50$ & $\$ 7494.50$ \\
\hline & \multicolumn{2}{|l|}{305.5} & \multicolumn{2}{|l|}{188} & \multicolumn{2}{|l|}{270.5} & 125 & 58 & 309 \\
\hline Other costs (\$) & \multicolumn{2}{|l|}{$\$ 4171.84$} & \multicolumn{2}{|l|}{$\$ 12,346.95$} & \multicolumn{2}{|l|}{$\$ 6767.12$} & $\$ 9312.40$ & $\$ 2251.17$ & $\$ 7113.60$ \\
\hline
\end{tabular}

${ }^{\mathrm{a}}$ Organization receiving grant

${ }^{\text {b }}$ Site 1 data is incomplete as CBO partner did not collect data. Site 2 had limited data from clinic's implementation period

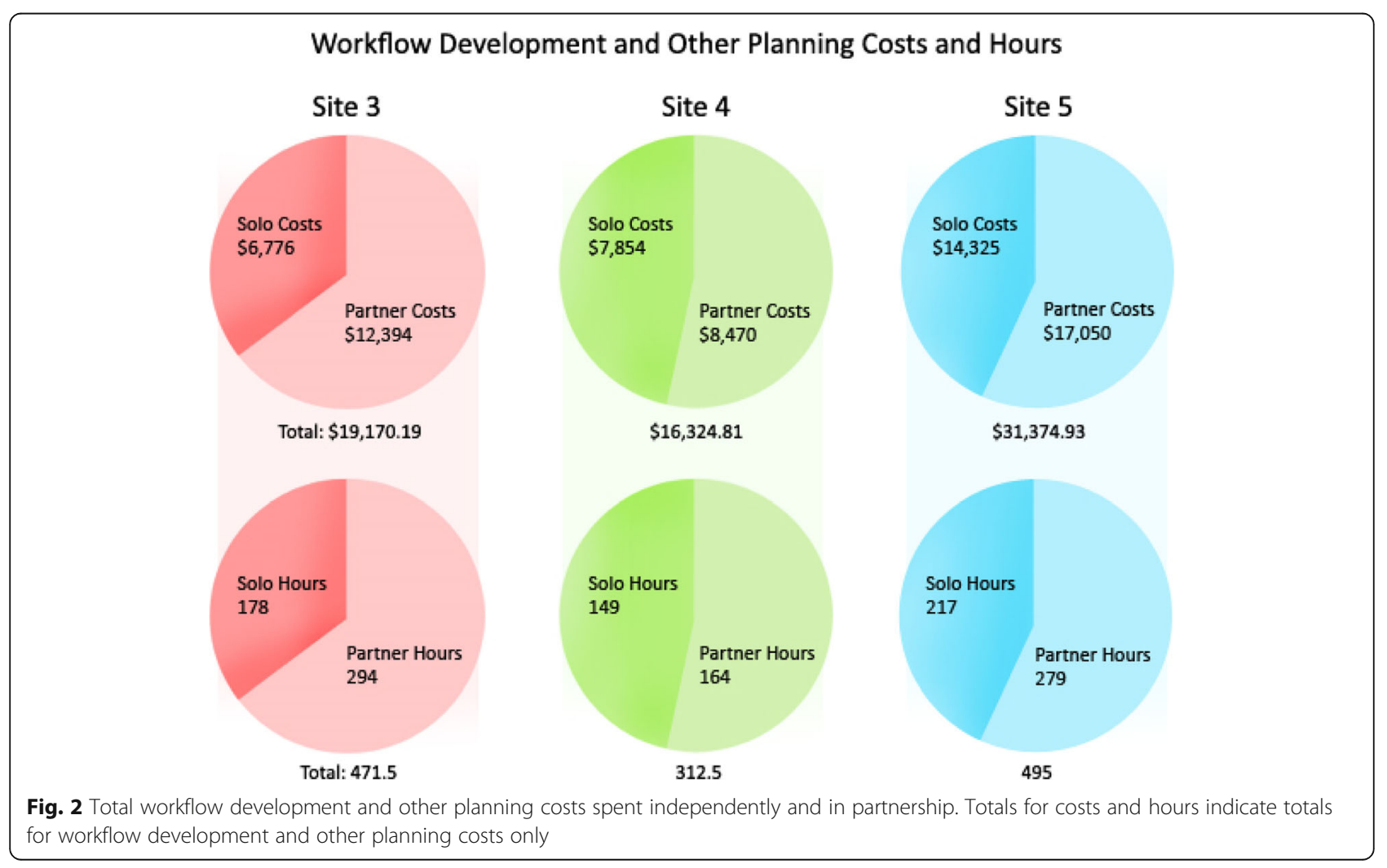


Table 3 Total planning and implementation costs across sites by phases of implementation (cost and time spent)

\begin{tabular}{|c|c|c|c|c|c|c|c|c|c|}
\hline \multirow[t]{2}{*}{ Organization } & \multicolumn{3}{|c|}{ Planning phase } & \multicolumn{3}{|c|}{ Implementation phase } & \multicolumn{3}{|l|}{ Total } \\
\hline & Hours & $\operatorname{cost}^{b}$ & Days in phase & Hours & $\operatorname{Cost}^{\mathrm{b}}$ & Days in phase & Hours & $\operatorname{cost}^{b}$ & Cost $+30 \%$ overhead \\
\hline Site 3 clinic $^{a}$ & 256.5 & $\$ 11,286.95$ & & 233 & $\$ 10,136.42$ & & 489.5 & $\$ 21,423.37$ & \\
\hline CBO partner & 100 & $\$ 5462.33$ & 155 & 83 & $\$ 3329.30$ & 269 & 183 & $\$ 8791.63$ & $\$ 39,279.50$ \\
\hline Site $4 \mathrm{CBO}^{\mathrm{a}}$ & 510.5 & $\$ 25,339.65$ & & 27.5 & $\$ 681.80$ & & 538 & $\$ 26,021.45$ & \\
\hline Clinic partner & 158 & $\$ 17,236.66$ & 161 & 5.5 & $\$ 444.70$ & 72 & 163.5 & $\$ 17,681.36$ & $\$ 56,813.65$ \\
\hline Site $5 \mathrm{CBO}^{\mathrm{a}}$ & 301 & $\$ 20,863.00$ & & 92.5 & $\$ 5420.81$ & & 393.5 & $\$ 26,283.81$ & \\
\hline Clinic partner & 221 & $\$ 17,254.52$ & 128 & 46 & $\$ 3057.71$ & 108 & 267 & $\$ 20,312.23$ & $\$ 60,574.85$ \\
\hline Family site 7 clinic & 280.5 & $\$ 29,402.93$ & 248 & 61 & $\$ 4721.89$ & 55 & 341.5 & $\$ 34,124.81$ & $\$ 44,362.25$ \\
\hline Site 1 clinic $^{\text {ac }}$ & 189 & $\$ 16,179.37$ & 182 & 73 & $\$ 6947.20$ & 163 & 262 & $\$ 23,126.57$ & $\$ 30,064.54^{c}$ \\
\hline Site $2 \mathrm{CBO}^{\mathrm{a}}$ & 1012.5 & $\$ 28,875.60$ & & 139 & $\$ 3313.70$ & & 1151.5 & $\$ 32,189.30$ & \\
\hline Clinic partner $^{\mathrm{c}}$ & 141.5 & $\$ 7416.26$ & 252 & 15 & $\$ 815.37$ & 134 & 156.5 & $\$ 8231.63$ & $\$ 52,547.21^{\mathrm{c}}$ \\
\hline
\end{tabular}

${ }^{\mathrm{a} O r g a n i z a t i o n}$ receiving grant

bHourly wage $+30 \%$ benefits

'Site has incomplete data. Site 1 data is incomplete as CBO partner did not collect data. Site 2 had limited data from clinic's implementation period, thus clinic implementation costs and total costs for site are underestimated

organization that received the grant spent more hours in the planning and implementation periods than their partner organization, though the difference in hours was more pronounced for sites 3 and 4 compared to site 5 . Though CBO data was unavailable, clinic costs for site 1 were comparable to the other clinics' costs in the planning and implementation periods. Implementation costs for the site 2 clinic are low due to limited data from this period that was reported by the $\mathrm{CBO}$ contact following turnover of the clinic contact.

\section{Costs of care}

We received complete cost of care data from four sites, three involving a $\mathrm{CBO}$ and one including family care partners. One $\mathrm{CBO}$ collected data even though their partner clinic declined participation after the clinic decided not to sustain the existing model (site 6). The CBO costs for this site amounted to $\$ 46$ per patient treated that month, which are not reported in Table 4 . One clinic collected data on costs after their partnership with the $\mathrm{CBO}$ formally ended, and they had implemented a new program that incorporated a new clinic case manager to actively engage patients in social services out in the community (site 1). Another site that saw their formal partnership dissolve was not able to collect cost of care data, as they did not implement their new model of care by the end of the grant period (site 2). Both partnerships ended in part due to an unexpectedly low number of patients that were using services at both partnering organizations (i.e., $\mathrm{CBO}$ and clinic).

Total program costs per patient treated for 1 month of care, including the 30\% overhead adjustment, ranged from $\$ 154$ to $\$ 541$ across sites with complete data. Across all sites, enrollment was relatively low, likely increasing the average cost per patient treated.
Care management costs varied by organization, and some organizations focused more on activities such as finding patients or caring for patients. Across clinic- $\mathrm{CBO}$ sites with complete data, one showed higher care manager costs for the $\mathrm{CBO}$, one showed higher costs for the clinic, and the third had relatively equal costs between $\mathrm{CBO}$ and clinic care managers. Subcategories in the care manager activities were not delineated in the data collection spreadsheets but developed upon thematic review of these activities. Travel was an area of data collection that was not specifically requested as a care manager activity and was thus not consistently reported. Travel time is not typically part of collaborative care programs and was only reported for one site offering home visits (site 4). Total care manager costs across sites with complete data ranged from $\$ 825$ to $\$ 3047$ in clinics and $\$ 465$ to $\$ 5047$ in CBOs. The highest costs for care management among the CBOs did not account for $51 \mathrm{~h}$ of in-kind time from the intern care manager (site 4). Charting activities and time finding patients could not be consistently separated from caring for patients at all sites but are reported separately for sites that reported a clear delineation between these activities.

Costs related to strategic decision-making and program administration continued in this sustaining phase of implementation, as sites used meeting times to discuss patients and to continue to make changes to their programs. These costs ranged from $\$ 284$ to $\$ 2328$ total over the 1-month data collection period among the sites with complete data. These costs were particularly high for two of the clinic-CBO partnerships that typically involved a greater number of individuals in their administrative meetings (sites 3 and 5). Care manager supervision outside the weekly case review with the psychiatric consultant and administrative management were 
Table 4 One month costs of care delivery in the sustainment period following implementation, total, and by number of patients treated during month

\begin{tabular}{|c|c|c|c|c|c|c|c|c|c|c|c|}
\hline Activity & $\begin{array}{l}\text { Site } 3 \\
\text { Clinic }\end{array}$ & $\begin{array}{c}\text { CBO } \\
\text { Partner }\end{array}$ & Site Total & Site 4 CBO & $\begin{array}{c}\text { Clinic } \\
\text { Partner }\end{array}$ & Site Total & Site 5 CBO & $\begin{array}{c}\text { Clinic } \\
\text { Partner }\end{array}$ & Site Total & $\begin{array}{c}\text { Site } 7 \\
\text { Clinic Total }\end{array}$ & \begin{tabular}{|c|} 
Site 1 \\
Clinic Total \\
\end{tabular} \\
\hline Care Manager Time Total & $\$ 2,340.00$ & $\$ 1,002.30$ & $\$ 3,342.30$ & $\$ 5,047.19$ & $\$ 1,010.00$ & $\$ 6,057.19$ & $\$ 3,422.18$ & $\$ 3,046.55$ & $\$ 6,468.73$ & $\$ 825.02$ & $\$ 3,861.88$ \\
\hline Finding Patients & $\$ 1,160.90$ & 618.80 & & & $\$ 576.86$ & & 77.53 & $\$ \quad 167.70$ & & $\mathrm{a}$ & $\$ 770.35$ \\
\hline Caring for Patients & 403.00 & 383.50 & & $\$ 2,842.32$ & 300.64 & & $\$ 3,344.65$ & $\$ 2,375.75$ & & 450.01 & $\$ 2,316.51$ \\
\hline Charting / Notes & 776.10 & a & & $\$ 1,012.44$ & 132.50 & & a & $\$ 503.10$ & & $\$ 375.01$ & $\$ 775.03$ \\
\hline Travel & & & & $\$ 1,192.43$ & & & b & & & & \\
\hline $\begin{array}{l}\text { Psychiatric Consultant } \\
\text { and PCP Time }\end{array}$ & $\$ 863.46$ & & $\$ 863.46$ & & $\$ 480.01$ & $\$ 480.01$ & & $\$ 859.48$ & $\$ 859.48$ & $\$ \quad 46.88$ & $\$ 1,590.06$ \\
\hline IT / QI Time & 115.70 & & $\$ 115.70$ & $\$ 172.50$ & & $\$ 172.50$ & $\$ 111.54$ & $\$ 175.50$ & $\$ 287.04$ & & \\
\hline $\begin{array}{l}\text { Strategic Decision } \\
\text { Making / Care Manager } \\
\text { Supervision / } \\
\text { Administrative }\end{array}$ & & & & & & & & & & & \\
\hline Management & $\$ 1,996.54$ & 331.50 & $\$ 2,328.04$ & $\$ 619.97$ & $\$ 862.52$ & $\$ 1,482.49$ & $\$ 1,066.28$ & $\$ 1,235.30$ & $\$ 2,301.58$ & $\$ 1,256.28$ & 284.00 \\
\hline Other Costs & $\$ 72.80$ & & $\$ 72.80$ & $\$ 170.00$ & & $\$ 170.00$ & & $\$ 442.20$ & $\$ 442.20$ & & $\$ 548.60$ \\
\hline Number of Patients & & & 17 & & & 20 & & & 34 & 18 & 17 \\
\hline Total Hours & 137 & 33 & & 144 & 40 & & 87.3 & 101 & & 34 & 119 \\
\hline $\begin{array}{l}\text { Total Cost Per Patient } \\
\text { ( }+30 \% \text { benefits) }\end{array}$ & $\$ 316.97$ & 78.46 & $\$ 395.43$ & $\$ 300.48$ & \$ 117.63 & $\$ 418.11$ & $\$ 135.30$ & $\$ 169.38$ & $\$ 304.68$ & $\$ 118.23$ & $\$ 369.68$ \\
\hline $\begin{array}{l}\text { Total Cost Per Patient } \\
\text { ( }+30 \% \text { overhead) }\end{array}$ & & & $\$ 514.06$ & & & $\$ 543.54$ & & & $\$ 396.08$ & $\$ 153.70$ & $\$ 480.58$ \\
\hline
\end{tabular}

$a$ costs included in time caring for patients category

$b$ travel costs notably missing for this site that offered regular home visits

included in this category, as these activities often overlapped in regular meetings.

Other notable costs also varied across sites. Non-billable time for the psychiatric consultant and PCP champion ranged from $\$ 47$ to $\$ 1590$ total over the 1-month data collection period, though most sites reported between $\$ 480$ and $\$ 859$ on such costs. The site that utilized only $\$ 47$ for psychiatric consultant involvement in care underutilized this resource both due to shorter weekly case reviews for half of the 1-month period and vacation falling over the other half of the month. IT and QI activities were minimal for most sites and typically involved a QI review of the caseloads to prepare progress reports to the grant funder. Such QI activities overlap with how sites are predicted to maintain oversight on care manager activities and plan for future patient workflow improvements; they are therefore included in Table 4 despite being considered grant-specific activities during the data collection period. Other staff and non-personnel costs were reported for three organizations but were minimal, with costs including front desk support for depression screening and travel expenses (e.g., mileage).

\section{Discussion}

High costs of care delivery over 1 month can be largely attributed to low enrollment at all sites and continued costs of strategic decision-making/administrative support/ supervision at all but site 1 . The primary reasons for low enrollment were (1) the limited number of shared patients across the $\mathrm{CBO}$ and clinic for some sites and (2) low motivation among those with late-life depression to access care from the clinic and $\mathrm{CBO}$ if the $\mathrm{CBO}$ staff were not providing home visits. For example, older adults with depression from the clinic were reluctant to venture to a senior center even with additional supportive outreach and, for some, arranged transportation to the CBO. Site 1 had higher costs of psychiatric consultant and primary care champion time however which may have included some of these administrative activities such as advertising the program across the clinics and attempting to increase enrollment. Site 7 had notably low costs for psychiatric consultant/PCP time. Sites 4 and 5 had higher care manager costs, and both sites involved home visits by the $\mathrm{CBO}$ staff. In comparison with previous collaborative care studies without community linkages, these costs are high relative to the original IMPACT collaborative care study [10, 13] and TEAMCare study which focused on comorbid depression with physical illness (e.g., diabetes and/or cardiovascular disease) $[25,26]$ but more comparable to a recent implementation of TEAMCare known as the COMPASS study from which these methods were based $[24,27]$ (personal communication with Michael Maciosek on June 14, 2018). The methods in this study were developed to account for additional non-billable and often hidden costs (e.g., program administration) that may not be estimated in other cost of care studies. Continued strategic decision-making and administrative costs during the 1-month period were also higher than anticipated, perhaps 
due to sites' ongoing efforts to increase enrollment in these new innovative programs involving family and/or CBO care partners. We plan to assess the cost of care again in the next year as sites continue to develop more scalable and sustainable programs (e.g., through increased enrollment and different staffing compositions).

As mentioned in the results, sites 1 and 2 lost their partnering organizations during the grant period. Site 1 revised their program to incorporate a case manager in the depression care team who is more active in working with $\mathrm{CBOs}$ out in the community. Site 2 eventually shifted to a home visit collaborative care program out in the community that allows them to work with community members seeing providers at a variety of primary care clinics. We have used the cost evaluation data to coach site 1 on sustainability of their new program and will collect data from site 2 in the coming year to help them with sustaining their new program as well.

Planning and implementation costs also varied across sites and were lower across organizations than comparable costs in the COMPASS study implementation of collaborative care (personal communication with $\mathrm{Mi}$ chael Maciosek on June 14, 2018). COMPASS planning and implementation costs supported implementation at health systems consisting of approximately 10-50 clinics, while most Care Partners sites implemented their program at one clinic initially explaining higher costs in COMPASS. The Care Partners site that spent the most overall in the planning + implementation periods and also the most on workflow development + other planning activities was the most successful model to develop within the first 2 years of the late-life initiative (site 5). This site's success was evident based on (1) their efforts to build the infrastructure to communicate about patients and improve workflows when needed, (2) total patient recruitment, and (3) improved depression symptoms. We speculate that this might be related to the strength of each organization's infrastructure and commitment of these partners to the partnered collaborative care program. Both organizations also brought to the table two evidencebased programs to improve late-life depression; the clinic implemented collaborative care, and the $\mathrm{CBO}$ used an existing Healthy Ideas program to reach individuals in their homes and offer additional depression education, behavioral activation, and case management support. Their complex patient population often consisted of patients with which they were working independently prior to the program's development, and now the $\mathrm{CBO}$ was able to share insights to the clinic on the home environment and additional case management support in the home or by phone from the $\mathrm{CBO}$ home visiting care manager. In contrast, site 3 reported approximately the same amount of time on planning and implementation activities, though the split between the $\mathrm{CBO}$ and the clinic was less even and their total costs associated with this time was lower. Through the larger evaluation of implementations across the seven sites within which this smaller cost study fell, we learned that site 3 struggled to include higher-level leadership as champions for improving depression screening, depression care, and referrals to their collaborative care program-a difference that may be reflected in this site's lower overall planning and implementation costs. The contrast between site 3 and site 5 highlights the potential insights that can be gathered from collecting planning and implementation costs when organizations partner to implement a new program. Partnership work faces its own challenges and may depend on synergy among the partnering organizations at the beginning of the implementation and throughout [27], but also on ongoing commitment from leadership at each organization that can help build that synergy. Tracking costs of implementation associated with successful partnerships could highlight areas of focus for potentially less successful partnerships and perhaps reduce some inefficiencies associated with faltering partnerships.

Other studies could learn from this approach to collecting costs and utilize similar spreadsheets to study implementation and sustainability of evidence-based practices, either with or without community partners. Administrators are interested in the planning and implementation costs they may face in planning for practice change. Some speculate that without these costs, administrators may overestimate costs [28]. Clinic leaders weigh costs and benefits but may focus more heavily on costs when making decisions [29]. Based on prior experiences implementing, administrators also may feel burnout related to implementing evidence-based practices if previous costs to implement were higher than expected (personal communication with Lisa Saldana on June 22, 2018). The benefit of the spreadsheet approach that we utilized was our ability to both (1) gather information retrospectively on planning + implementation costs and (2) present a simple data collection tool that could gather prospective cost of care data from site contacts with regular support from our study team. One promising web-based tool known as the Cost of Implementing New Strategies (COINS) offers support for prospectively collecting planning + implementation costs across all stages of implementation outlined in the Stages of Implementation Completion (SIC) [30]. The SIC is a tool that can support implementation more generally or be tailored to specific implementations like collaborative care. Prospective data collection is ideal to avoid some recall bias and loss of information due to turnover of key staff or ending of formal partnerships. However, COINS data must be collected with the SIC, adding to the level of data collection overall, but offering SIC data that describes implementation progress. For most sites, we were able to successfully collect 
planning + implementation cost data given (1) limited lag time between the grant award date and data collection and (2) appropriate guidance documents and technical assistance support. As these data collection activities were not specified in the original grant agreements for sites, we included substantial honoraria to facilitate data collection and compensate for time spent on these activities-a total of $\$ 500$ for each organization.

The spreadsheet approach is also a simple way to collect cost of care data during the sustainment period that can be tailored to an evidence-based practice, including any unique adaptations such as adding community partners to the program. We collected this data at one time point between 2 and 9 months following the end of the sites' implementation periods. Cost of care spreadsheets could be collected repeatedly during the sustainment period so sites can maintain fidelity to the evidence-based program but address any inefficiencies to improve sustainability. Additional data collection beyond the cost of care spreadsheets may also be helpful to capture costs of sustainability that may not arise in these 1-month snapshots such as training new staff following turnover and training boosters to promote fidelity during the sustainment period. Collecting these additional training costs during the sustainment period is an important avenue for future research.

Limitations included the retrospective nature of data collection for planning + implementation costs and turnover within sites, including turnover among staff and leadership holding key information on planning + implementation activities. Two sites also faced challenges within their partnerships that resulted in them dissolving their formal partnerships. Despite these limitations, with moderate technical assistance support and a reasonable honorarium, we were able to collect complete planning + implementation data on more than half of the sites and complete data on several of the other organizations even when their partner's data could not be completed. We delayed data collection on costs of care for sites that needed more time (e.g., to revise workflows following the end of a formal partnership for this program) and thus have more complete data on costs of care at the sites. Costs of care data was more complete due to the prospective nature of data collection, shorter time to complete this spreadsheet, and our emphasis that this information is more immediately relevant to the sites when planning for sustainability. We also split the $\$ 500$ honorarium such that sites were further incentivized to complete the second spreadsheet on cost of care data.

Partnering with community agencies and to some degree family members in care is the direction health care is heading at a national level, yet planning and implementation costs associated with such partnerships are seldom studied or reported. Clinics are increasingly collecting health-related social and behavioral measures in EHRs, which is partially motivated by existing linkages between clinics and community-based resources. These measures motivate deeper connections with social service agencies as was evidenced in the development of several of the enhanced collaborative care programs in this implementation project. Such partnership work is aligned with the work happening within many Accountable Care Organizations and developing Accountable Health Communities. California and Washington State for example have developed Accountable Communities of Health that focus on community organizations that can serve as a bridge to build an infrastructure between clinics and CBOs. Partnership work will require time and regular meetings to develop these relationships and plan future directions and methods to evaluate their work together, time that is often not accounted for in the implementation of evidencebased interventions.

\section{Conclusion}

Implementing and sustaining partnered innovations requires substantial financial resources and time, resources that are often not studied given that information on planning and implementation costs in more traditional implementations are often not collected. Such partnership work can improve services for older adults and patients with complex health and social service needs. While many factors will affect a partnership's potential for long-term success, indicators of potential challenges may be reflected in each organization's planning and implementation costs (e.g., limited leadership involvement). Such cost information can thus help future partnerships implementing evidence-based programs predict costs for certain activities and plan accordingly. Cost of care data is particularly helpful for sites in planning to sustain their newly implemented programs. Assessing such costs in future studies is feasible and can inform future partnership efforts to implement evidence-based programs within Accountable Care Organizations and Accountable Health Communities.

\section{Additional file}

Additional file 1: Cost categories in Excel data collection spreadsheets. (DOCX 25 kb)

\section{Abbreviations}

CBO: Community-based organizations; CHWs: Community health workers; EHR: Electronic health record; IT: Information technology; LCSW: Licensed clinical social worker; PCC: Primary care clinic; PCP: Primary care provider; QI: Quality improvement; VA: Veterans Administration

\section{Acknowledgements}

We would like to thank the contacts at each site for their diligence and support in data collection and Katherine James for research support in the preparation of this manuscript. We would also like to thank Michael Maciosek (HealthPartners), Chuan-Fen Liu (Veterans Administration and University of Washington) and Carol Levine (University of Washington) for 
helpful guidance on the development of our study plan and interpretation of findings.

\section{Funding}

We would like to acknowledge funding for this work from the Archstone Foundation.

\section{Availability of data and materials}

The datasets generated and analyzed during the study are not publicly available due to the sensitive nature of cost data but are available from the corresponding author on reasonable request.

\section{Authors' contributions}

$\mathrm{TH}, J \mathrm{U}$, and HW participated in study development and conception of the paper. TH and HW collected and analyzed the data. All authors participated in drafting and revising the manuscript. All authors read and approved the final manuscript.

\section{Ethics approval and consent to participate}

The larger Care Partners evaluation was reviewed by the University of Washington and University of California Davis IRBs and determined to be exempt. The subsequently funded cost evaluation was discussed with the University of Washington IRB and self-determined to be exempt based on the larger parent grant's exempt status.

\section{Consent for publication}

We consent to publication.

\section{Competing interests}

The authors declare that they have no competing interests.

\section{Publisher's Note}

Springer Nature remains neutral with regard to jurisdictional claims in published maps and institutional affiliations.

\section{Author details}

${ }^{1}$ Department of Psychiatry and Behavioral Sciences, University of Washington School of Medicine, Box 356560, Seattle, WA 98195-6560, USA. ²Department of Psychiatry and Behavioral Sciences, University of California, Davis, CA, USA.

Received: 10 December 2018 Accepted: 25 March 2019

\section{Published online: 18 April 2019}

\section{References}

1. Lyness JM, Caine ED, King DA, Cox C, Yoediono Z. Psychiatric disorders in older primary care patients. J Gen Intern Med. 1999;14(4):249-54.

2. Blazer DG. Depression in late life: review and commentary. J Gerontol A Biol Sci Med Sci. 2003:58(3):249-65.

3. Mojtabai R, Olfson M. Major depression in community-dwelling middleaged and older adults: prevalence and 2- and 4-year follow-up symptoms. Psychol Med. 2004;34(4):623-34.

4. Byers AL, Yaffe K, Covinsky KE, Friedman MB, Bruce ML. High occurrence of mood and anxiety disorders among older adults: the National Comorbidity Survey Replication. Arch Gen Psychiatry. 2010;67(5):489-96.

5. Unutzer J, Patrick DL, Diehr P, Simon G, Grembowski D, Katon W. Quality adjusted life years in older adults with depressive symptoms and chronic medical disorders. Int Psychogeriatr. 2000;12(1):15-33.

6. Alexopoulos GS, Vrontou C, Kakuma T, Meyers BS, Young RC, Klausner E, et al. Disability in geriatric depression. Am J Psychiatry. 1996;153(7):877-85.

7. Unutzer J, Patrick DL, Simon G, Grembowski D, Walker E, Rutter $C$, et al. Depressive symptoms and the cost of health services in $\mathrm{HMO}$ patients aged 65 years and older. A 4-year prospective study. JAMA. 1997;277(20):1618-23.

8. Katon WJ. The Institute of Medicine "Chasm" report: implications for depression collaborative care models. Gen Hosp Psychiatry. 2003;25(4):222-9.

9. Conwell $Y$, Duberstein PR, Caine ED. Risk factors for suicide in later life. Biol Psychiatry. 2002;52(3):193-204.

10. Unutzer J, Katon W, Callahan CM, Williams JW Jr, Hunkeler E, Harpole L, et al. Collaborative care management of late-life depression in the primary care setting: a randomized controlled trial. JAMA. 2002;288(22):2836-45.

11. Bruce ML, Ten Have TR, Reynolds CF 3rd, Katz II, Schulberg HC, Mulsant BH, et al. Reducing suicidal ideation and depressive symptoms in depressed older primary care patients: a randomized controlled trial. JAMA. 2004; 291(9):1081-91.

12. Archer J, Bower P, Gilbody S, Lovell K, Richards D, Gask L, et al. Collaborative care for depression and anxiety problems. Cochrane Database Syst Rev. 2012;10:CD006525

13. Unutzer J. Evidence-based treatments for anxiety and depression: lost in translation? Depress Anxiety. 2008;25(9):726-9.

14. Hinton L, Zweifach M, Oishi S, Tang L, Unutzer J. Gender disparities in the treatment of late-life depression: qualitative and quantitative findings from the IMPACT trial. Am J Geriatr Psychiatry. 2006;14(10):884-92.

15. Hinton L, Apesoa-Varano EC, Gonzalez HM, Aguilar-Gaxiola S, DwightJohnson M, Barker JC, et al. Falling through the cracks: gaps in depression treatment among older Mexican-origin and white men. Int J Geriatr Psychiatry. 2012;27(12):1283-90.

16. Hoeft TJ, Hinton L, Liu J, Unutzer J. Directions for effectiveness research to improve health services for late-life depression in the United States. Am J Geriatr Psychiatry. 2016;24(1):18-30.

17. Hoeft TJ, Fortney JC, Patel V, Unutzer J. Task-sharing approaches to improve mental health care in rural and other low-resource settings: a systematic review. J Rural Health. 2018;34(1):48-62.

18. World Health Organization. Task shifting: rational redistribution of tasks among health workforce teams: global recommendations and guidelines. 2007. http:// apps.who.int/iris/bitstream/handle/10665/43821/9789241596312_eng.pdf; jsessionid=A57FF358211ECDF2EA0D2D015BFB3F4D? sequence $=1$. Accessed 22 June 2018.

19. Patel V, Goel DS, Desai R. Scaling up services for mental and neurological disorders in low-resource settings. Int Health. 2009;1(1):37-44.

20. Patel V. Global mental health: from science to action. Harv Rev Psychiatry. 2012;20(1):6-12.

21. National Academies of Sciences, Engineering, and Medicine. Systems practices for the care of socially at-risk populations. Washington, DC: National Academies Press; 2016.

22. Long P, Abrams M, Milstein A, Anderson G, Lewis Apton K, Lund Dahlberg $M$, et al., Editors. Effective care for high-need patients: opportunities for improving outcomes, value, and health. Washington, DC: National Academy Of Medicine; 2017

23. Coleman KJ, Magnan S, Neely C, Solberg L, Beck A, Trevis J, et al. The COMPASS initiative: description of a nationwide collaborative approach to the care of patients with depression and diabetes and/or cardiovascular disease. Gen Hosp Psychiatry. 2017;44:69-76.

24. Rossom RC, Solberg LI, Magnan S, Crain AL, Beck A, Coleman KJ, et al. Impact of a national collaborative care initiative for patients with depression and diabetes or cardiovascular disease. Gen Hosp Psychiatry. 2017:44:77-85.

25. Katon WJ, Lin EH, Von Korff M, Ciechanowski P, Ludman EJ, Young B, et al. Collaborative care for patients with depression and chronic illnesses. N Engl J Med. 2010;363(27):2611-20.

26. Katon W, Russo J, Lin EH, Schmittdiel J, Ciechanowski P, Ludman E, et al. Cost-effectiveness of a multicondition collaborative care intervention: a randomized controlled trial. Arch Gen Psychiatry. 2012;69(5):506-14.

27. Lasker RD, Weiss ES, Miller R. Partnership synergy: a practical framework for studying and strengthening the collaborative advantage. Milbank Q. 2001; 79(2):179-205 III-IV.

28. Smith MW, Barnett PG. The role of economics in the QUERI program: QUERI Series. Implement Sci. 2008:3:20.

29. Palinkas LA, Um MY, Jeong $\mathrm{CH}$, Chor KHB, Olin S, Horwitz SM, et al. Adoption of innovative and evidence-based practices for children and adolescents in state-supported mental health clinics: a qualitative study. Health Res Pol Syst. 2017;15(1):27

30. Saldana L. The stages of implementation completion for evidence-based practice: protocol for a mixed methods study. Implement Sci. 2014;9(1):43. 